\title{
TYPE OF HERBAL MEDICINES UTILIZED BY PREGNANT WOMEN ATTENDING ANTE-NATAL CLINIC IN OFFINSO NORTH DISTRICT: ARE ORTHODOX PRESCRIBERS AWARE?
}

\author{
Y. ADUSI-POKU ${ }^{1}$, L. VANOTOO ${ }^{2}$, E. K. DETOH ${ }^{3}$, J. ODURO $^{4}$, R. B. NSIAH ${ }^{1}$ and \\ A. Z. NATOGMAH ${ }^{4}$ \\ ${ }^{1}$ District Health Directorate, Offinso North District, Ashanti Ghana ${ }^{2}$ Regional Health Directorate, Greater \\ Accra, Ghana ${ }^{3}$ Nkenkaasu District Hospital, Offinso North District, Ashanti Ghana ${ }^{4}$ Regional Health Direc- \\ torate, Ashanti, Ghana ${ }^{4}$ Akomadan Health Centre, Offinso North, Ashanti
}

DOI: http://dx.doi.org/10.4314/gmj.v49i4.2 Corresponding Author: Dr. Yaw Adusi-Poku

Conflict of Interest: Non declared

\section{SUMMARY}

Background: There is scanty data on the usage and safety of herbal medicines in pregnancy and breast feeding. Though they may be efficacious on account of their long experience of usage, effects of these herbal preparations and the extent of usage in pregnancy and breastfeeding are not known. There were anecdotal claims of herbal medicine usage in pregnancy in Offinso North District.

Objective: To determine the prevalence and the pattern of herbal medicine usage among pregnant women attending ANC in all the health facilities in Offinso North District and to determine the level of awareness of healthcare givers about these herbal medicines.

Design: Cross-sectional study.

Method: A standardized structured questionnaire was administered to pregnant women attending antenatal clinics in the Offinso North district.

Results: Age of respondents ranged from 15-49 years among which 25 (6.5\%) took herbal medicines through varying routes of administration. High usage was found amongst those married and also with no formal and basic education and a median age of 25 years. Awareness of orthodox health practitioners about these herbal medicines was scanty.

Conclusions: The study emphasized the use of herbal medicines particularly through some unconventional mode of preparations by pregnant women in Offinso North. Orthodox practitioners' awareness of their usage was found to be inadequate, highlighting an urgent need for health care practitioners and other health care givers to be aware of this practice and make efforts in obtaining information about herb use during ante-natal care.

Key Words: Herbal Medicines; Pregnancy; Ghana, Sub-Saharan Africa.
E-mail:togobay@yahoo.com

\section{INTRODUCTION}

Herbal medicines have been used since the pre-colonial era in Ghana. While there are claims of the efficacy of some of these herbs, there is scanty data on its usage and safety in pregnancy and breastfeeding. ${ }^{1}$ If taken in addition to other orthodox medicines, much is not known about the pharmacologic interactions. One study found out that use of some herbal medicines were associated with a $30 \%$ lower ongoing pregnancy and live birth rate during fertility treatment. ${ }^{2}$

Other studies indicated that some herbs may amplify the effects of anticoagulants while some, including common fruits, interfere with cytochrome P450 enzyme systems which are critical to drug metabolism. ${ }^{3,4}$ More so, orthodox healthcare givers have little knowledge of these herbal medicines to advise clients. $^{5,9}$

Again, concerns are constantly being raised by policymakers, government officials, orthodox health professionals and researchers on the efficacy, quality, reliability and safety of herbal medicines. ${ }^{10}$ For instance, out of over six hundred herbal medicine products circulating per year, only a little above two hundred undergo preliminary phyto-chemical analysis and safety test per year at the Centre for Plant Medicine Research (CPMR) and its satellite units. ${ }^{10}$

CPMR, is the institution mandated by the Ghana government to undertake research and development of plant medicine, and to assess and approve the efficacy, long term safety and clinical monitoring of herbal medicine products in Ghana.

In addition to these concerns, some registered products do not adhere to Good Manufacturing Practices (GMP). 
This occurs as a result of poor regulatory framework for the manufacturing, importation and the distribution of herbal medicines. ${ }^{1,12}$ Therefore, doubts continue to linger in the minds of policy-makers, government officials, and orthodox health professionals about quality, efficacy safety, and reliability of herbal medicine. ${ }^{12}$

Offinso North, in the Ashanti Region of Ghana is predominantly rural, geographical access to healthcare is a problem. The land size of Offinso North is 741 square kilometers, total population for 2014 was 63277; hence a population density of 85.4-persons/square kilometer. ${ }^{13}$ Antenatal coverage in 2014 was $99.7 \%$

There are anecdotal claims that pregnant women take herbal medicines but little is known about the type, the route of administration and their use. More so, these herbs are introduced into the body through various routes such as enema and drinking.

The objective of this study was to determine the prevalence and the pattern of herbal medicine use among pregnant women attending ANC in all the health facilities in Offinso North District and to determine the knowledge of healthcare givers of these herbal medicines. Result of this study would very much inform the District Health Management Team (DHMT).

\section{METHOD}

The study design was a descriptive cross-sectional. The sample size was calculated to be 385 to detect a $50 \%$ prevalence of pregnant women who took herbal medicine at $95 \%$ confidence interval. A non-response rate of $5 \%$ was added to make the sample size total 401 . ANC attendance in the health facilities in the Offinso North district was high. Hence it was assumed that almost all pregnant women attended ANC in the facilities.

The study was conducted in all the four health facilities in the Offinso North district between June and August 2014 among confirmed pregnant women of any gestation. Some facilities had attendances more than their expected pregnancies with respect to their catchment area hence during the sampling of participants for the study, at a facility where the number of registrants for ANC was larger than the quota allotted based on the expected pregnancies in the catchment area (calculated based on the percentage of women in fertility age in 2014), systematic random sampling method was used. However, in other facilities simple random sampling method was conducted.
A structured open-ended questionnaire was designed to document the frequency of herbal usage, the medicinal use(s) and the form of herbal medicine as well as the route of administration.

The demography of respondents was also obtained. A second questionnaire was developed for orthodox practitioners to assess their awareness of herbal medicines used by pregnant women in the district

Herbal medicine, also called botanical medicine or phytomedicine, was defined as herb, herbal material, herbal preparation, and finished herbal product that contains parts of plants or other plant materials as active ingredients ${ }^{1}$.The plant materials include seeds, berries, roots, leaves, bark or flowers. ${ }^{1}$ Data were analysed using Epi Info 7. Descriptive statistics were used.

\section{RESULTS}

Three hundred and eighty-four (384) questionnaires were retrieved for analysis. Hence the response rate was $95.8 \%$. Table 1 shows the reproductive characteristics of the studied pregnant women.

Table 1 Personal and reproductive characteristics of the studied pregnant women in Offinso North District

\begin{tabular}{|l|l|l|}
\hline Characteristic & No. & $\%$ \\
\hline Age (median, range) & 27 & $(15-49)$ \\
\hline Marital Status & & \\
Married & 255 & 66.4 \\
Cohabiting & 98 & 25.5 \\
Never married & 30 & 7.8 \\
Divorced & 1 & 0.26 \\
\hline Educational Status & & \\
No formal education & 173 & 45.1 \\
Basic (Junior high) & 152 & 39.6 \\
Senior High(or Equivalent) & 31 & 8.1 \\
Tertiary & 28 & 7.3 \\
\hline Religion & & \\
Christianity & 302 & 78.7 \\
Islam & 73 & 19.0 \\
Traditional & 9 & 2.3 \\
\hline Gestation at recruitment & & \\
Mean(sd) & 24 weeks & $(s d 2.13)$ \\
Median gestational age & 24 weeks & $(12-36)$ \\
\hline First baby & & \\
Yes & 32 & 8.3 \\
\hline Previous pregnancy losses & & \\
Termination of pregnancy & 14 & 3.6 \\
Stillbirth> 28 weeks gestation; & & \\
Still/Neonatal death & 10 & 2.6 \\
\hline
\end{tabular}

Source, DHA, 2014

Table 2 shows the background characteristics of the 25 $(6.5 \%)$ pregnant women who took herbal medicines. 
Table 2 Background characteristics of pregnant women attending ANC who took herbal medicine $(n=25)$ in Offinso North District.

\begin{tabular}{|l|l|l|}
\hline Characteristic & No. & $\%$ \\
\hline Age (range) & 25 & $(17-47)$ \\
\hline Marital Status & & \\
Married & 15 & 60.0 \\
Cohabiting & 8 & 32.0 \\
Divorced & 1 & 4.0 \\
Never married & 1 & 4.0 \\
\hline Educational Status & & \\
Basic (Junior high) & 14 & 56.0 \\
No formal education & 5 & 20.0 \\
Senior High (or Equivalent) & 3 & 12.0 \\
Tertiary & 3 & 12.0 \\
\hline Religion & & \\
Christianity & 22 & 88.0 \\
Islam & 3 & 12.0 \\
\hline Gestation at recruitment & & \\
Mean(sd) & 26 weeks & $(s d 1.28)$ \\
Median gestational age & 26 weeks & $(12-36)$ \\
\hline First baby & & \\
Yes & 8 & 32.0 \\
\hline Previous pregnancy losses & & \\
Termination of pregnancy & 7 & 28.0 \\
Stillbirth> 28 weeks gestation & & \\
Neonatal death & & \\
& & \\
\hline Source, DHA 2014 & \\
\hline
\end{tabular}

Source, DHA, 2014

Herbal medicines taken by pregnant women attending antenatal clinics were identified as follows: Cassia occidentalis 15(40.5\%); Sida acuta and Cola gigantea $6(16.3 \%)$ respectively; Annona senegalensis and Nauclea latifolia, 5(13.5\%) respectively.

For Sida acuta and Cola gigantea, the part of the plant (roots, leaves or bark) were grounded, mixed with water, and used as an enema. In addition, "Red soil" was added in the case of Cola gigantea before introducing the enema. The other herbs were prepared in the form of decoction or soup for drinking.

Majority, (99.0\%) of pregnant women indicated that the source of acquisition of the herbal medicines was through ancestral practice and the reason for their usage was to aid in easy labour and delivery and to improve on foetal outome.

Among the categories of health practitioners who were interviewed, including a doctor, physician assistants, pharmacists and nurses totaling 29, none of them in their interactions with the pregnant women asked about their herbal medications and less than half, 9(31.0\%) were aware pregnant women took herbal medicines.
Of the herbal medicines listed above, only 3(10.3\%) of the health care providers knew Annona senegalensis as being used in pregnancy.

\section{DISCUSSION}

The prevalence of pregnant women taking herbal medicines in the Offinso North District was 6.5\%. This is relatively low compared with other similar studies in Sub-saharan Africa- $12 \%$ in Kenya in a district hospi$\operatorname{tal}^{14} ; 50.4 \%$ in Ethiopia ${ }^{15}$ and $50.0 \%$ in Harere. ${ }^{16}$ For this study in Offinso North district, pregnant women were asked open-ended questions to assess whether they used any herbal medicines during pregnancy. Open-ended questions yield lower percentage for answers. ${ }^{17}$ Again, the questions centered on herbal products that were used solely for medicinal purposes and excluded those consumed as nutrients. These may have accounted for the relatively low prevalence.

Women with "basic" and "no formal education" with a median age of 25 years used herbal medicine more than women with senior high and tertiary education. Bodeker and Kronenberg obtained similar results where women with no formal or only primary education used herbal medicines more. ${ }^{18}$ Other sources have indicated contrary results, that women who use herbal medicines are characterized as having higher education and income levels. ${ }^{19,20}$ Therefore, it must be pointed out that several of the factors associated with herbal medicine users vary from one study to another and appears to reflect whether it is a community study or simply, pregnant women attending ANC in a health facility. ${ }^{19}$

Majority, (99.0\%) of pregnant women indicated that the source of acquisition of the herbal medicines was through ancestral practice. This goes to buttress the point that some of the more complex reasons for preference of herbal medicines are associated with cultural and personal beliefs, philosophical views on life and health $^{19,21}$. Several authors have also suggested that this may well reflect a woman's desire to have a natural approach to pregnancy ${ }^{22,23}$ or perhaps these women feel a desire to use less conventional medication. This could represent a concern, as studies have found that women will often not communicate the use of herbal medicines to their health care providers. ${ }^{24,25}$

Some reasons given for the use of herbal medicines by pregnant women in Offinso North were for well-being of the fetus (to improve on fetal outcome) and to aid in easy labour and delivery. 
Hence it was necessary to compare the reasons given by these women to the literature of these herbal medicines - traditional uses, active principle, measured activity as well as toxicity studies.

\section{Cassia occidentalis}

Traditionally, it is used for bacterial and or fungal infections as well as liver disorders (jaundice, hepatitis, cirrhosis, detoxification) and as an antioxidant. ${ }^{26}$ The aerial parts, leaves and roots have been studied and the active principles include achrosine, emodin, anthraquinones, apigenin, sitosterols, tannins and xanthones. ${ }^{26,27}$ It has invitro antibacterial activity against E. coli and Salmonella typhi. ${ }^{26}$ Toxicity studies on the aerial parts and leaves as well as roots of $C$. occidentalis reported that various leaf and root extracts (administered orally and injected at up to $500 \mathrm{mg} / \mathrm{kg}$ ) given, caused mice mortality. $^{26,27}$

\section{Sida acuta}

It has been traditionally used to treat malaria, fever, ulcer, gonorrhea, abortion, breast cancer, poisoning; and it also stops bleeding. The Leaves, roots as well as whole plant contain alkaloids- cryptolepine; quindolinon and 11-methoxyquindoline. There has been a laboratory demonstrable activity against plasmodia and has chemo-preventive properties ${ }^{28 .}$ Toxicity studies did not show clinical correlations (causing harm). ${ }^{29,30}$

\section{Cola gigantea}

It is used in the treatment of sores, skin infections, and other inflammatory conditions including osteoarthritis. The bark contains alkaloids, saponins, tannins, caffeine, cardenolides. It has been demonstrated to be a bronchodilator, a CNS stimulant and anti-microbial. ${ }^{30,31}$ Acute toxicity of the crude extract conducted did not reveal harmful effects in animals. ${ }^{32}$

\section{Annona senegalensis}

It is traditionally used as a CNS stimulant and for pain relief. The leaves, fruits, flowers bark, and stem contain triterpenes, anthocyanes, glucids, coumarins, flavonoids and alkaloids. ${ }^{33}$ It has a demonstrable invitro activity against plasmodia, also a chemotherapeutic and antioxidant. $^{34}$ The root-bark is safe at lower doses but cautioned at higher doses $(\mathrm{P}<0.05){ }^{35}$

\section{Nauclea latifolia}

Anecdotally, it is used traditionally to arrest pre-term labour, treat fever and diabetes. The roots and leaves contain sugar, saponins, and flavonoids as well as Indole alkaloids. ${ }^{36,37}$ It has time and concentration dependent potential to cause hepato and nephrotoxic effects on rats. ${ }^{36}$
Documentation of the above plants for use in pregnancy is rare. In general, it is accepted that plants commonly used in traditional medicine are assumed to be safe due to their long usage in the treatment of diseases according to knowledge accumulated over centuries. However, recent scientific findings has shown that many plants used as food or in traditional medicine are potentially toxic, mutagenic and carcinogenic. ${ }^{38,39}$

It was of concern that orthodox practitioners generally had low level of awareness of the herbs that were being used. Whereas these pregnant women would not voluntarily disclose these herbs, it was a practice that orthodox practitioners did not routinely inquire from their patients. This situation is compounded by the fact that the teaching of traditional herbal medicine is not included in the curricula of the nation's medical schools and nurses' training colleges and yet about $70 \%$ of Ghanaians take in herbal medicine. ${ }^{40}$ This underscores the need for physicians and other healthcare providers to be knowledgeable of these herbal therapies that their patients are taking in order that they can advise them for the sake of optimal clinical care.

\section{LIMITATIONS}

The study was conducted from June to August, 2014; therefore it did not reflect the representativeness of pregnant women attending ANC throughout the year. This might have affected the prevalence of herbal intake. More so, some of the women would not disclose their herbal intake status for fear of being reprimanded.

\section{CONCLUSIONS}

The study emphasized the use of herbal medicines particularly through some unconventional mode of preparations by pregnant women in Offinso North. Orthodox practitioners' awareness of their usage was found to be inadequate, highlighting an urgent need for health care practitioners and other health care givers to be aware of this practice and make efforts in obtaining information about herb use during ante-natal care. This will help forestall possible interaction between herbal and conventional medicines.

\section{ACKNOWLEDGMENTS}

We are most grateful to all orthodox practitioners and all pregnant women in the Offinso North district.

\section{REFERENCES}

1. WHO Media Centre. Traditional Medicine Fact sheet No. 134; 2008. Available at: http://www.who.int/mediacentre/factsheets/fs134/e $\mathrm{n} /$ (Accessed June 2015) 
2. Bolvin J, Schmidt L. Use of Complementary and Alternative Medicines Associated with a 30\% Lower Ongoing Pregnancy/Live Birth Rate During 12 months of Fertility Treatment. Human Reproduction 2009; 21 (7):1626 - 1631

3. Spolarich AE, Andrews L. An Examination of the Bleeding Complications Associated with Herbal Supplements, Anti Platelet and Anti - Coagulant Medications. J. Diet Hyg. 2007;81 (3) : 67.

4. Nekvindova J, Anzenbacher P. Interactions of Food and Dietary Supplements with Drug Metabolising Cytochrome P450 Enzymes. Ceska Slov Farm 2007; 56 (4): 165 - 73

5. Mabina MH, Pitsoe SB, Moodley J. The effect of traditional herbal medicines on pregnancy outcome. S Afr Med J 1997, 87:1008-10.

6. Maats F, Crowther C. Patterns of vitamin, mineral and herbal supplement use prior to and during pregnancy. Aust N Z J Obs Gyn 2002, 42:494-6.

7. Ernst E: Herbal medicinal products during pregnancy: are they safe? Brit J Obs Gyn 2002, 109:227-35.

8. Tsui B, Dennehy C, Tsourounis C. A survey of dietary supplement use during pregnancy at an academic medical center. Am J Obs Gyn 2001, 185:433-7.

9. Lacroix I, Damase-Michael C, Lapeyre-Mestre M, Montastrue JL. Prescription drugs during pregnancy in France. Lancet 2000, 356:1735-1736.

10. Centre for Plant Medicine Research. Research Factsheet 2014. Mampong Akuapem.

11. Tsui B, Dennehy C, Tsourounis C. A Survey of Dietary Supplement Use During Pregnancy at An Academic Medical Center. Am J Obstet Gynaecol 2001; 185 - 433 - 437.

12. Wambebe C. Regulatory Frameowk for Local Production of Herbal Medicine in Africa. Bolelin Latinoamericanoy del caribe de plantas. Medicinales Aromaticus 2009; 8: 2 - 6

13. District Health Management Team Studies. Demographic Factsheet, Offinso North District. Ashanti.

14. Mothupi MC. Use of herbal medicine during pregnancy among women with access to public healthcare in Nairobi, Kenya: a cross-sectional survey. BMC Complementary and Alternative Medicine 2014,14:432. Accessed: http://www.biomedcentral.com/1472-6882/14/432

15. Mbura JS, Mgaya HN, Heggenhougen HK. The use of oral herbal medicine by women attending antenatal clinics in urban and rural Tanga district. East African Medical Journal. 1985 Aug; 62(8):540-50 - Accessed at: http://www.popline.org/node/417846\#sthash.SEw
3YdkG.dpufhttp://www.popline.org/node/417846. Accessed September 5, 2015.

16. Mureyi DD, Monera TG, Maponga CC. Prevalence and patterns of prenatal use of traditional medicine among women at selected Harare clinics: a cross-sectional study. BMC Complementary and Alternative Medicine 201212:164. doi:10.1186/1472-6882-12-164.

17. Reja U, Manfreda LK, Hlebec V, Vehovar V. Open-ended vs.Close-ended Questions in Web Questionnaires. Faculty of Social Sciences, University of Ljubljana ploscad 5, 1000 Ljubljana, Slovenia.

18. Bodeker G, Kronenberg F. A Public Health Agenda for Traditional, Complementary and A1ternative Medicine. Am J Public Health 2002, 92(10):1582-1591

19. Frawley J, Adams J, Sibbritt D, Steel A, Broom A, Gallois C. Prevalence and determinants of complementary and alternative medicine use during pregnancy: results from a nationally representative sample of Australian pregnant women. Aust N Z J Obstet Gynaecolol 2013, 53(4):347-352.

20. Holst L, Wright D, Haavik S, Nordeng H, The use and the user of herbal remedies during pregnancy. J Altern Complement Med 2009, 15(7):787-792

21. Hall HG, Griffiths DL, McKenna LG. The use of complementary and alternative medicine by pregnant women: a literature review. Midwifery2011, 27(6):817-824

22. Ernst E, White A. The BBC survey of complementary medicine use in the UK. Compl Ther Med 2000, 8:32-6.

23. Astin JA. Why patients use alternative medicine? Results of a national study. J Am Med Ass 1998, 279:1548-53.

24. Frawley J, Adams J, Sibbritt D, Steel A, Broom A, Gallois C. Prevalence and determinants of complementary and alternative medicine use during pregnancy: results from a nationally representative sample of Australian pregnant women. Aust N Z J Obstet Gynaecol 2013, 53 (4):347-352.

25a. Holst L, Wright D, Nordeng H, Haavik S. Use of herbal preparations during pregnancy: focus group discussion among expectant mothers attending a hospital antenatal clinic in Norwich, UK.Complement Ther Clin Pract 2009,15(4):225229.

25b. Holst L, Wright D, Haavik S, Nordeng H. The use and the user of herbal remedies during pregnancy. J Altern Complement Med 2009, 15(7):787-792

26. Sadiq IS, Shuaibu M, Bello AB, Tureta SG, Isah A, Izuagie T, Nasiru S, Kamaru MB. Phytochemistry and Antimicrobial Activities of Cassia Occi- 
dentalis Used for Herbal Remedies. Journal of Chemical Engineering. January 2012Vol. 1, No. 1

27. Bin-Hafeez B. and Hussaini AS. Protective effect of Cassia Occidentalis L. on Cyclophosphamideinduced suppression of humoral immunity in mile journal Ethnopharmacol. 2001, 75(1); 13-18

28. Chidambara K; Yanitha A, Mahadeva M, Ravishankar G. Antioxodiant and antimicrobial activity of cissie guandrangularis L. Journal of medicinal food 2003; 6: 2. 10

29. Karou SD, Nadembega WMC, IIboudo DP, Ouermi D, Gbeasso M, Souza CD, Simpore J. Sida acuta Burm,f.: a medicinal plant with numerous potencies. African Journal of Biotechnology 2007. vol.6 (25), pp. 2953-2959. Accessed www.ajol.info/index.php/ajb/article/viewFile/5827 $0 / 46627$

30. Konaté K, Imaël BHN, Hilou A, Raïssa ARR, Souza A, Barro N, Mamoudou DH, Datté JY, M'Batch B. Toxicity assessment and analgesic activity investigation of aqueous acetone extracts of Sida acuta Burn f . and Sida cordifolia L. (Malvaceae), medicinal plants of Burkina Faso. BMC Complementary and Alternative Medicine 2012, 12:120. Accessed at http://www.biomedcentral.com/1472-6882/12/120

31. Burkill HM. The useful Plants of West Tropical Africa, 2000; 2nd Edition. Vol 5, Families Sâ€“Z, search Addenda: Cola gigantea. Royal Botanic Gardens, Kew, Richmond, United Kingdom. 686 pp.

32. Oteng-Amoako AA. 100 tropical African timber trees from Ghana: tree description and wood identification with notes on distribution, ecology, silviculture, ethnobotany and wood uses. (Editor), $2006304 \mathrm{pp}$

33. Odion EE, Poh CF, Falodun A, Adelusi SA, Rostrata C. Phytochemical and Toxicity Studies. J. Appl. Sci. Environ. Manage. December 2013. Vol. 17 (4) 603-607
34. Mustapha AA. Annona senegalensis Persoon: A Multipurpose shrub, its Phytotherapic, Phytopharmacological and Phytomedicinal Uses International Journal of Science and Technology Volume 2 No. 12, December, 2013

35. Okoye TC, Akah PA, Ezike AC, Okoye MO, Onyeto CA, Ndukwu F, Ohaegbulam E, Ikele L. Evaluation of the acute and sub-acute toxicity of Annona senegalensis root bark extract. Asian Pac J Trop Med. 2012. (4):277-82. doi: 10.1016/S19957645(12)60039-X.

36. Nworgu ZM, Owolabi O J, Atomah J E. Effect of the ethanolic extract of Nauclea latifolia (Family: Rubiaceae) on the isolated uterus of non-pregnant rats. Int J Green Pharm [serial online] 2010 [cited: 2015 Mar 17]; 4:48-53. Available from: http://www.greenpharmacy.info/text.asp?2010/4/1/ 48/62162

37. Arise RO, Akintola AA, Olarinoye JB, Balogun, EA. Effects of Aqueous Extract of Nauclea latifolia Stem on Lipid Profile and Some Enzymes of Rat Liver and Kidney. International Journal of Pharmacology 2012; 8: 389-395

38. Schimmer O, Kruger A, Paulini H, and Haefele F.). An evaluation of 55 commercial plant extracts in the Ames mutagenicity test. Pharmazie 1994; 49:448 - 451

39. De Sã Ferrira ICF and Ferrão VVM. Mutagenicity of medicinal plant extracts in salmonella/microsome assay. Phytother. Res. 1999. 13:397 -400 .

40. Asante A. Scientific Medical Practitioners and Traditional Medicine in Contemporary Ghana: A Study of Attitudes and Perceptions. A Thesis Submitted to the Department of Sociology and Anthropology of The Faculty Of Social Sciences, University Of Cape Coast, In Partial Fulfilment of The Requirements for Award Of Master Of Philosophy Degree In Sociology, $2010 \bullet$ 